\title{
APPLICATION OF JI KOUTEI KANKETSU IN HIGHWAYS DESIGN PROCESS IMPROVEMENT
}

\author{
Quynh Anh Nguyen ${ }^{1}$, Lauri Koskela ${ }^{2}$, Doug Potter ${ }^{3}$, Algan Tezel ${ }^{4}$, Barbara Pedo ${ }^{5}$, \\ and Patricia Tzortzopoulos ${ }^{6}$
}

\begin{abstract}
This paper provides an introduction to 'Ji Koutei Kanketsu' (JKK) as a recently developed Lean method and illustrates its potential to support the improvement of BIM-based highways design work processes. JKK is developed based on the concept of jidoka to enhance the autonomation in non-physical work processes. This method provides the employees the confidence to complete their own processes without defects, while requiring a strong collaboration between the managers and their teams. The paper is based on an action research study for trialing the use of JKK in a large engineering company. It is concluded that $\mathrm{JKK}$, when its prescription is compared to the current state, focuses attention to the following issues: defining individual work activities, their support factors, their pre-conditions, the judgment criteria of their outputs, and continuous improvement. $\mathrm{JKK}$ is also evaluated by comparing it to other, overlapping methods.
\end{abstract}

\section{KEYWORDS}

Lean, BIM, jidoka, ji koutei kanketsu.

\section{INTRODUCTION}

Ji Koutei Kanketsu (JKK) is a Japanese term which refers to a practice in White Collar departments at Toyota (Manabe 2014). JKK means 'completing your own process' which relates to the philosophy of 'jidoka' - expanding the autonomation in each employee's work. This method requires strong collaboration between the personnel, and a deep understanding of their own working process and that of others'. It also looks deeply into business for its process, purposes/targets, work elements, work condition, and judgement criteria (Manabe 2014). JKK implementation is evaluated as a success at Toyota; however, there has not been many studies about its implementation in other types of industry or in

1 PhD student, School of Art, Design and Architecture, Univ. of Huddersfield, Queensgate, Huddersfield UK, quynhanh.nguyen@ @ud.ac.uk, orcid.org/0000-0003-0945-6584

2 Professor, School of Art, Design and Architecture, Univ. of Huddersfield, Queensgate, Huddersfield UK, 1.koskela@hud.ac.uk, orcid.org/0000-0003-4449-2281

3 Associate Technical Director \& CDM Principal Designer Manager, Arcadis Consulting (UK) Ltd, Manchester UK, doug.potter@arcadis.com, orcid.org/0000-0003-1681-9785

4 Senior Lecturer, School of Art, Design and Architecture, Univ. of Huddersfield, Queensgate, Huddersfield UK, a.tezel@hud.ac.uk, orcid.org/0000-0003-3903-6126

$5 \quad \mathrm{PhD}$ student and KTP Associate, School of Art, Design and Architecture, Univ. of Huddersfield, Queensgate, Huddersfield UK, b.pedo@hud.ac.uk, orcid.org/0000-0002-6520-0981

6 Associate Dean of Research, School of Art, Design and Architecture, Univ. of Huddersfield, Queensgate, Huddersfield UK, p.tzortzopoulos@ hud.ac.uk, orcid.org/0000-0002-8740-6753 
countries other than Japan. Because of its novelty, there is a lack of academic research into JKK in general, and especially of its implementation in the construction industry. The study of Manabe (2014) ${ }^{7}$ is the only English academic source which provides a comprehensive description of JKK. This paper is a part of an action research which aims to test the application of JKK in a real context of highway projects in terms of process improvement. Hence, its main aim is to present the JKK method and initially evaluate it regarding its suitability for construction contexts. This is done, firstly, by introducing the concept of JKK and comparing it to the other methods and tools that have aligned elements. The comparison is to support the understanding of how JKK stands out from other existing methods. Secondly, the prescriptions of JKK are compared to the current state of a selected (partial) process of a highways design project in a global engineering company that has a branch in the UK.

\section{RESEARCH METHOD}

The underlying research is being carried out as action research. This paper partly describes the first two phases of the action research, covering an introduction of JKK as a new method, and its initial application as an evaluation tool in a selected specific process. The introduction of JKK is carried out through literature review, which also includes the comparison JKK to other relevant methods to define the overlaps and differences. Then, $\mathrm{JKK}$ as an evaluation tool is used to analyse the process performance in a particular project. The data on process performance is collected via open and semi-structured interview methods.

\section{JI KOUTEI KANKETSU}

According to Liker (2004), 'jidoka', known as built-in quality, also refers to 'autonomation' which allows the production line to be halted with human intelligence when a problem arises. In other words, jidoka gives the employees the power to stop the production line when they detect an issue. The importance of jidoka is related to its support to the just-in-time (JIT) system in terms of reducing variability. Remarkably, in jidoka, quality is treated as a factor inside production instead of an outcome of production (Koskela et al. 2019).

Since the 1960s, the concepts of JIT and jidoka have been applied widely in physical production; however, in 2007 Toyota decided to apply jidoka to all departments (Manabe 2014). Due to the different characteristic of the work between the physical production department and other departments, Toyota's attempt did not fulfil its expectations (Manabe 2014). Unable to apply the original jidoka concept, Toyota developed a new concept, known as Ji Koutei Kanketsu or JKK, which enhances the autonomation with a different approach. The concept of JKK is briefly introduced in Masai (2017) and Heller and Fujimoto (2017) as a built-in quality with ownership. The main goal of JKK is to ensure the clarity on work inputs and outputs, and the understanding of how one's personal work suits into the whole processes in which such work is placed (Heller and

7 The study of Manabe (2014) - "Applying the Autonomation Concept to White-Colla Departments at Toyota Motors: The Basics of JKK (Ji Koutei Kanketsu)" was firstly presented at the $22^{\text {nd }}$ International Colloquium of GERPISA conference by Seiji Manabe. Since then, it has been updated as a working paper series with the involvement of Daniel Heller. The latest version of this study (version 5) can be found

at https://www.researchgate.net/publication/340827257_Applying_the_Autonomation_Concept_to_Wh ite_Collar_Departments_at_Toyota_Motors_The_Basics_of_JKK_Ji_Koutei_Kanketsu 
Fujimoto 2017). The study of Manabe (2014, cited in Heller and Fujimoto 2017, p.107) shows that JKK is also about getting the employees to understand their co-workers' work and to treat them as customers.

The JKK implementation route is a six-step procedure (Figure 1), which primarily focuses on improvement of individual activities (the mentioned authors do not distinguish between activities and processes consisting of activities; for clarity we use the activity when dealing with the smallest elements) to ensure that each individual activity is executed accurately (Manabe 2014). Accordingly, the entie process should run smoothly with zero defects.

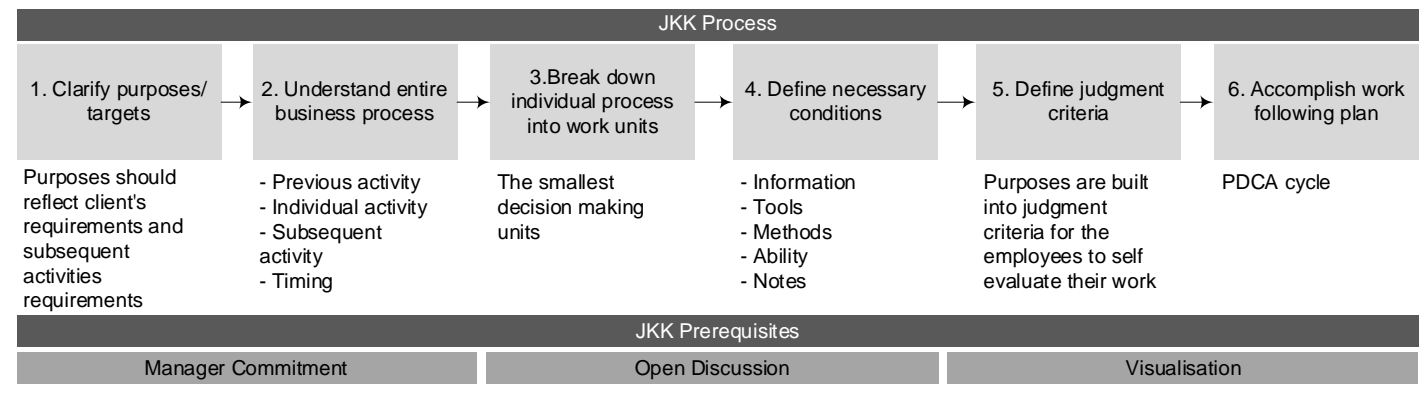

Figure 1: JKK implementation procedure and prerequisites.

Drawn based on (Manabe 2014)

The first step of JKK is to clarify the work purposes/targets. At this step, the purposes and performance targets, indeed all the requirements from the client and the subsequent activities, should be identified (Manabe 2014). Beside defining the purposes/targets of the whole business process, the purposes of individual activities also need to be pinpointed as it effects on the successful of JKK implementation (Manabe 2014). The second step is to understand the business processes as chunks which encompass the previous activity, individual activity, and the subsequent activity. The previous activity in the process provides the information for the individual activity, which receives the transferred information, processes it and then delivers to the subsequent activity. Both content and transfer time of information are important at this step. After clearly understanding the activities as well as work purposes/targets, the next step is to break down the individual activity into work units, which indicate the 'smallest decisionmaking units' where the person in charge can make his/her own decision and which does not require the involvement of the superior. In order to do so, the organisation must have a clear standard for the crucial conditions and judgment criteria, from which the employee can make his/her own decision with the confidence of not passing the defects into subsequent activity (Manabe 2014).

The definition of the necessary conditions of work is in step 4 in the JKK procedure. Work in the individual activity can only begin if the essential conditions for producing the output are met. The essential conditions include information, tools, methods, ability to carry out the work, and notes, which are past experience from previous works. The person in charge can start the work if he/she gets adequate input information, software, devices, guidance, and training. After all essential conditions are at hand, the work can be carried out. The fifth step in the JKK framework refers to the identification of the judgement criteria, which form the basis to assess if the work meets the requirements. In other words, how the person in charge will know if the quality of his/her work meets the standards and requirements before passing it to the subsequent activity. The judgment 
criteria should be built based on the purposes/targets which are already defined in the first step of JKK. The final step is to regularly accomplish the Plan-Do-Check-Act (PDCA) cycle in management. Applying the PDCA cycle into the JKK framework is presented in Figure 2.

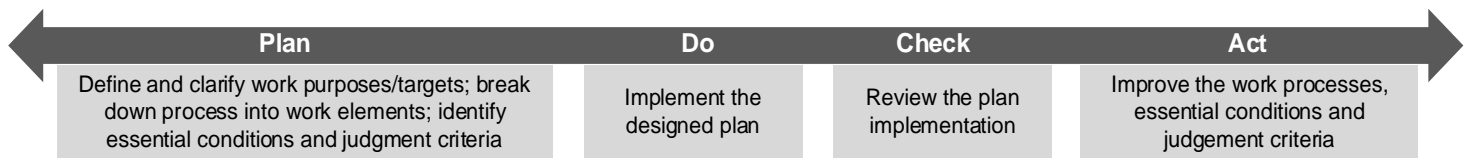

Figure 2: The PDCA cycle in the JKK implementation.

Drawn based on (Manabe 2014).

JKK implementation cannot be achieved without three crucial prerequisites: visualisation, open discussion, and manager commitment (which refers to the roles and duties of the managers) (Manabe 2014). The manager needs to comprehensively prepare their employees to commence JKK and to closely engage in the employees' work. Five main duties of the managers as part of manager commitment include: (1) to raise awareness of employees, (2) to operate a JKK working environment, (3) to encourage applying the PDCA in daily management, (4) to clearly understand which work cannot be performed in compliance with JKK, to promote its improvement, and (5) to develop the organisational area of JKK.

The purpose of visualisation in JKK is to ensure the visibility of information so that it can be shared to solve the issues (Manabe 2014). The manager is responsible for maintaining such information visualisation. Besides, the manager also must create an environment for open discussion in which the employees can freely share their problems and search for diverse solutions. The open discussion feature in JKK enhances the principle of jidoka in terms of giving employees the chance to address problems as soon as they emerge. Indeed, this feature fits into one of the purposes of jidoka - "decouple the quality and the process from direct supervision" provided by Kitazuka and Moretti (2012). In physical production, this purpose of jidoka is often obtained by using poka yoke technique to detach the quality and the process from direct management by halting the operation as a problem occurs, and to require assistance to fix the process (Kitazuka and Moretti 2012). Alongside the manager responsibilities in JKK implementation, the employees are expected to continuously gain knowledge and skills, and to take responsibility for their own work, and to cooperate with others.

Sörkvist (2016) expresses the idea of JKK application based on his meeting with Mr. Sasaki - the JKK's originator, who worked in Toyota for nearly 50 years. JKK should be simple with the aim of everyone being able to understand and participate. In Toyota, JKK is applied at three levels, from top managers level, middle managers level to worker level.

$\mathrm{JKK}$ is recognised to provide up to eight benefits: improved quality of work, increased customer satisfaction, improved efficiency, active communication between departments, organisational memory for standards and knowhow, improved employee abilities, smooth job rotation, and enhanced employee motivation (Manabe 2014).

\section{COMPARISON OF JKK TO OTHER METHODS}

Similarly to prior methods, the main aim of JKK is to improve work quality; however, Toyota had to create a new one - JKK - to address intellectual work. Because of its novelty, and as its differences to prior methods are subtle, a comparison between JKK and aligned prior methods is made. 


\section{Process Modelling}

Process modelling not only brings benefits for the organisation, but it also improves the processes and the outputs for the client, according to the literature synthesis provided by Tzortzopoulos et al. (2005). Similarly, JKK offers benefits to the whole business process, activities and client through improving quality of work and increasing client satisfaction (Manabe 2014). In the JKK framework, understanding the business process is an obligatory activity. At this point, the similarity between JKK and process modelling is the necessity to comprehend the whole process. However, according to Tzortzopoulos et al. (2005), process modelling requires two model types (as-is and to-be) for understanding and improving the process, while in the JKK framework, it seems like it requires only the 'as-is' model for current practice, and then proceeds to expanding understanding of the individual process activities at a deeper level.

Another important factor that distinguishes JKK and process modelling is their focus. Understanding the process in terms of workflow is an important activity in both process modelling and JKK. However, in JKK, focusing on preparing for the outside factors of the activities, which are addressed in two steps in the framework (step 4 - define necessary conditions, step 5 - define judgement criteria), is as important as understanding the activities themselves, accordingly to Manabe (2014).

\section{TARGeT VALUE Design}

Target Value Design (TVD), is a version of target costing adapted to the construction industry (Zimina et al. 2012). It applies different methods to develop the design in accordance with a constraint such as cost (Miron et al. 2015). The core concept of TVD is to make the client's values a "driver of design", to meet the client's expectations as well as to reduce waste (Zimina et al. 2012). Thus, both TVD and JKK start from a definition of customer requirements. However, the focus in TVD is cost reduction, whereas in JKK, the central objective is how to achieve individual work performance with zero defects. Moreover, in JKK, internal customers are meticulously addressed, besides the external customer. In TVD, the emphasis is on achieving the constraints posed by the external customer.

\section{Last Planner System}

The Last Planner System (LPS) is a key method in lean construction (Ballard and Tommelein 2021). The main functions of the LPS include setting up tasks and milestones, planning/replanning to complete the tasks, achieving reliable promises, measuring the production system performance, and learning from the failures.

At the outset, it has to be stated that the Last Planner System and JKK are different regarding their purpose. The LPS is a method for production management in a project context, with emphasis on the short term. In turn, JKK is a method for ensuring the quality in intellectual work. JKK focuses more on giving the employee confidence to perform zero-defect work rather than making them to promise to complete a task according to agreed schedule.

However, there are interesting similarities. Removing constraints in the LPS and defining necessary work conditions in JKK share the same purpose in terms of preparation for a work operation. In turn, the term Conditions of Satisfaction (Ballard and Tommelein 2021) seems to be similar to judgment criteria of JKK. Furthermore, both methods rely on the PDCA cycle for realizing continuous improvement. 
Because the LPS, as such, is based on intellectual work, the prospect of considering the use of JKK as a support method to the LPS arises. However, this idea cannot be pursued further in this presentation.

\section{STANDARDISATION}

Among the lean production principles, standardisation is the baseline for continuous improvement and a key factor for building in quality (Liker 2004). When evaluating JKK from the standardisation viewpoint, it seems that the main aim of JKK is to set out a standard for product quality, working procedure, methodology, and techniques. Therefore, JKK can be considered as part of standardisation. The application of standardisation, as introduced by Liker (2004), is quite broad. Since JKK is part of standardisation, it provides a more specific direction for building standards in work processes and products, along with the implementation of continuous improvement.

\section{ANALYSIS OF THE CURRENT STATE THROUGH JKK}

\section{The Process of Design Risk Management}

The ongoing action research comprises of understanding and improving the BIM-based highway design sub-processes in a large engineering design company in the UK. These sub-processes play a vital role in providing information for the whole design process. Among the studied sub-processes, the Design Risk Management Process (DRMP) has been selected for this paper as its improvement is urgently needed. At the moment, the process is quite fragmented and it has not been standardised. The company is targeting to standardise and improve the DRMP so that it could be used in all types of highway projects, with some adjustment depending on each project's characteristics. The original name of DRMP is Hazard Elimination Schedule (HES), however, the company has changed the name to DRMP as part of their efforts in process improvement. DRMP complies with the Construction Design and Management (CDM) Regulations (2015), which is a legislatory document developed by the UK government to improve the handling of Health and Safety (H\&S) issues in all stages of the asset lifecycle and particularly during the pre-construction stage of a construction project (Zhou et al. 2012).

The main aim of the CDM regulations is to support designers in the planning, managing, and mitigating of design risks throughout the construction process, ensuring that stakeholders are involved in all aspects of health and safety during the design and construction process (Zhou et al. 2012). DRMP is a chain of activities to capture and eliminate all possible risks in design, construction, and maintenance stages by complying with the Principles of Prevention, which are addressed in The Management of Health and Safety at Work Regulation (1999). The process requires the involvement of the client, principal designer, designers, principal contractor, and subcontractors (Zhou et al. 2012).

The understanding of DRMP in the chosen company has been captured through a process mapping exercise. During design development, the designers use a design checklist to classify and assess each risk with regard to its severity and likelihood and then look to develop mitigation actions for it. In this phase, the risks are identified as initial risks. The designers' optimal mitigation solution is to eliminate as many risks as possible. After applying mitigation actions, such risks that cannot be eliminated, should be reduced to be as low as practicable prior to their transfer to the principal contractor during the construction phase. 
These risks are now known as residual risks. At the handover point, from design into the construction stage, all risks should be transferred from the design team to new (risk) owners, including the client, the principal contractor, and the maintainer as the designers should have completed their duties under the legislation by evidencing they have followed the DRMP.

The Principal Designer and Design Managers have the responsibility of reviewing and confirming their sub-ordinates' risk assessment and mitigation actions. In the construction stage, the principal contractor is responsible for developing any further mitigation actions for the residual risks. On completion of construction activities, any remaining risks will be passed to the client.

The term 'initial risk' and 'residual risk' are used to classify the current risk status, while the term 'generic risk' and 'specific risk' are used to classify them regarding risk location factor. Generic risks are those risks that are common and easy to manage and may be widespread across the construction site. Specific risks are those risks that are unusual and difficult to manage and are always defined by their specific location, being normally attached to a new or existing asset on the scheme.

The risks in a project are also classified into disciplinary categories which include Environment, Health and Safety, Geotechnical, Highway, Structure, Land, and Stakeholders. The number of risks defined in the scheme depends on scheme's scope and the risk impact related to disciplinary categories described above. It also depends on the location classification. For instance, a generic risk which impacts across a large number of assets will be converted into multiple specific risks by attaching it to all relevant assets. This can lead to a considerable increase in the number of risks within the project. In the project selected for this paper, the number of risks has increased from 3,000 risks to approximately 40,000 risks after attaching generic risks to all relevant assets. For H\&S purposes it is important that the Principal Contractor is aware of all risks, but it is the difficulty to identify and manage the risks that they need to pay particular attention to.

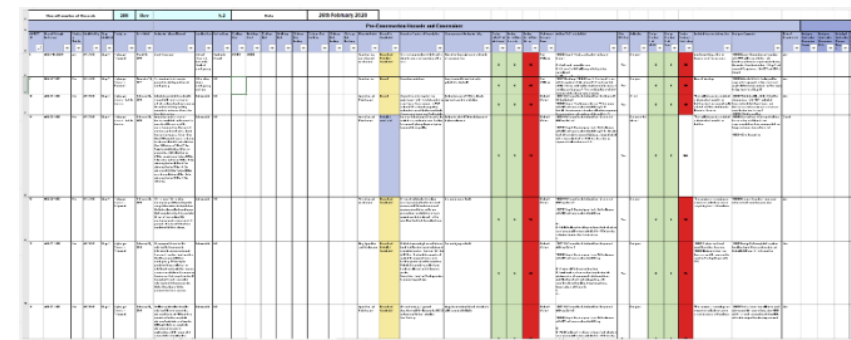

(a)

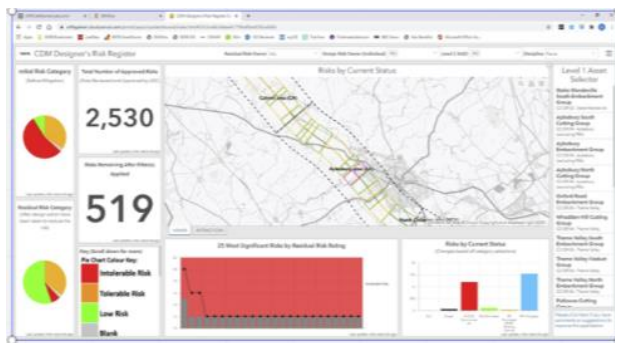

(b)

Figure 3: The Company's Design Risk Management Schedule in Excel spreadsheet (a) and in GIS platform (b)

The company has been using an electronic spreadsheet (Excel file) for risk management (Figure 3a); however, it has gradually replaced this traditional spreadsheet with an online platform (Geographic Information System - GIS) as a single source of information (Figure 3b). Instead of populating risk information into the spreadsheet, the designers can do the same activity in the GIS system, which provides the same information fields as the spreadsheet. The risk information in GIS is always up to date; therefore, the probability of missing information is low. The layout of the GIS platform is different in each project as it depends on the preference of the project. However, either the spreadsheet or GIS platform, risk information fields must always replicate the DRMP sequence and activities. The adoption of the GIS platform has not yet been widely applied due to project budget 
limitations. The use of the GIS platform also supports the integration of DRMP and BIM as the risks captured during the design stage can now be linked into the BIM model to assist locating risks and related design decision making. The risks are extracted from GIS layers in 2D drawings, then linked into the BIM model. Nevertheless, the integration of GIS and BIM is limited as currently data can only be updated within GIS and not from within the BIM software.

\section{Analysing of Design Risk Management Process through JKK in THE SELECTED PROJECT}

The DRMP varies across different projects due to differing requirements across various clients. Nevertheless, its main aim is the same in every project, namely capturing and, where possible, eliminating risks. JKK has not been applied in the DRMP in any project, thus it is only used here as an evaluation tool to assess the performance of the DRMP in a selected particular project. At the moment, the DRMP in this project has proceeded into the risk handover procedure; however, there are many issues which have emerged during the process. The evaluation is based on the result of an initial assessment of DRMP through nine interviews with the Principal Designer (PD) and Design Managers. The assessment provided evidence on wastes such as rework, inefficiency in information management and control, and lack of defined plan/process for transferring information. In order to understand the root causes of these wastes, a deeper assessment of every aspect inside the process is necessary. To identify the root causes of the wastes in the DRMP, the assessment elements for this action are built based on the JKK implementation procedure (Table 1) and its prerequisite factors.

In respect to manager commitment, one of the JKK prerequisites, the Principal Designer (PD) of this process has carried out a training workshop at the beginning of the process to ensure that all designers understand their responsibilities and the work procedure. However, the PD has assumed that the designers have achieved full understanding of the process without a firm validation that this is the case. Due to an incomplete process model, the PD also does not have a thorough view of how this process interacts with other processes. There is a lack of regular review workshops, which has led to delays in problem detection and solution. Indeed, the workshops were only organised after the PD received an audit from a third party. In addition, the work outputs are only reviewed near the end of each phase; this causes a heavy workload for both the PD and the designers.

Regarding the another prerequisite of JKK - open discussion and visualisation perspectives, there is also a lack of a collaborative platform and atmosphere, in which the designers can openly share their problems. For instance, when having technical problems, instead of discussing with the technology team and the PD, the designers try to solve the problems themselves. The GIS platform can be considered as a key part of the visualisation. It is used ideally as a repository for all risk information, as a single source of the truth, so that all designers can access and share the information. However, to access and use this platform, a license, under the control of another department, is needed. At the beginning of the process, the PD did not have a clear vision of who would need this license; therefore, the PD has had to request further access rights during the process progression. The request process is a time-consuming activity that leads to delays in the risk population activity. Moreover, the information fields in the GIS platform are not yet sufficiently reflecting the whole of the DRMP. For example, handover points, date system integration, risk approval processes, etc., are not captured in the current GIS platform. 
Table 1: JKK as an evaluation tool for Design Risk Management Process

\begin{tabular}{|c|c|c|c|}
\hline $\begin{array}{l}\text { Assessment } \\
\text { elements }\end{array}$ & $\begin{array}{l}\text { JKK requirements as } \\
\text { interpreted in the context } \\
\text { of DRMP }\end{array}$ & $\begin{array}{l}\text { Aspects of DRMP in } \\
\text { compliance to JKK } \\
\text { criteria }\end{array}$ & $\begin{array}{l}\text { Aspects of DRMP not in } \\
\text { compliance to JKK criteria }\end{array}$ \\
\hline $\begin{array}{l}\text { 1. Purposes } \\
\text { built based } \\
\text { on client's } \\
\text { requirement } \\
\text { s }\end{array}$ & $\begin{array}{l}\text { The purposes of the whole } \\
\text { process and individual } \\
\text { activities includes } \\
\text { capturing and eliminating } \\
\text { all possible risks in design, } \\
\text { and transferring a detailed } \\
\text { information set of risks to } \\
\text { the client and the } \\
\text { contractor. }\end{array}$ & $\begin{array}{l}\text { The main purpose of the } \\
\text { process is defined at the } \\
\text { early stage of the } \\
\text { project. }\end{array}$ & $\begin{array}{l}\text { Detailed client's requirements are } \\
\text { not specified, so have not been } \\
\text { explicitly converted into process } \\
\text { purposes/targets. }\end{array}$ \\
\hline \multirow[t]{2}{*}{$\begin{array}{l}2 . \\
\text { Understandi } \\
\text { ng the } \\
\text { process }\end{array}$} & \multirow[t]{2}{*}{$\begin{array}{l}\text { Understanding the whole } \\
\text { DRMP along with } \\
\text { individual activities inside } \\
\text { the process, also the } \\
\text { interaction with other } \\
\text { activities and processes } \\
\text { such as Pre-Construction } \\
\text { Information (PCI) process. }\end{array}$} & \multirow[t]{2}{*}{$\begin{array}{l}\text { Understanding the work } \\
\text { process has been } \\
\text { realised via training and } \\
\text { process management } \\
\text { plan, which presents the } \\
\text { process model in written } \\
\text { format and through a } \\
\text { high-level work diagram. }\end{array}$} & $\begin{array}{l}\text { The process is not clear and has } \\
\text { not been completed as it is being } \\
\text { updated during the project's } \\
\text { progression. The handover } \\
\text { procedure from the design stage } \\
\text { to the construction stage has not } \\
\text { been well defined. }\end{array}$ \\
\hline & & & $\begin{array}{l}\text { There is a lack of connection } \\
\text { between the DRMP and other } \\
\text { processes such as PCl process in } \\
\text { terms of providing information. }\end{array}$ \\
\hline $\begin{array}{l}3 . \\
\text { Breakdown } \\
\text { individual } \\
\text { activities } \\
\text { into work } \\
\text { units }\end{array}$ & $\begin{array}{l}\text { Understanding work units } \\
\text { in which the individual } \\
\text { decision making can be } \\
\text { done without approval from } \\
\text { managerial level. }\end{array}$ & & $\begin{array}{l}\text { There has not been any exercise } \\
\text { to define work units. }\end{array}$ \\
\hline \multirow{3}{*}{$\begin{array}{l}\text { 4. Necessary } \\
\text { conditions } \\
\text { (Input, Tool, } \\
\text { Methods, } \\
\text { Ability, } \\
\text { Notes/ Past } \\
\text { experience) }\end{array}$} & \multirow{3}{*}{$\begin{array}{l}\text { Necessary conditions for } \\
\text { DRMP comprise of input } \\
\text { from PCI process, } \\
\text { technical tool for } \\
\text { populating risk information } \\
\text { (Excel spreadsheet or GIS } \\
\text { platform depending on } \\
\text { each project's budget), } \\
\text { method for capturing risks, } \\
\text { ability to capture risks and } \\
\text { to propose elimination } \\
\text { solutions, lessons learned } \\
\text { from previous projects. }\end{array}$} & \multirow[t]{3}{*}{$\begin{array}{l}\text { The existing conditions } \\
\text { to carry out the work } \\
\text { include input information } \\
\text { provided by the client; } \\
\text { site surveys; a DRMP } \\
\text { management plan; a } \\
\text { technical tool for risk } \\
\text { management (GIS } \\
\text { platform) and a general } \\
\text { user guide. }\end{array}$} & $\begin{array}{l}\text { There is a lack of clear instructions } \\
\& \text { guidance for the employees to } \\
\text { carry out the work; likewise, there } \\
\text { is a lack of the past experience } \\
\text { from previous projects as there } \\
\text { has not been the opportunity to } \\
\text { capture and disseminate } \\
\text { information. }\end{array}$ \\
\hline & & & $\begin{array}{l}\text { The general user guidance of the } \\
\text { technical tool and process } \\
\text { instructions may not be sufficient } \\
\text { as there is evidence that the } \\
\text { designers have failed to populate } \\
\text { information correctly. }\end{array}$ \\
\hline & & & $\begin{array}{l}\text { The lesson learned activity has not } \\
\text { been organised to capture current } \\
\text { experience related to the } \\
\text { employees and the process for } \\
\text { future projects. }\end{array}$ \\
\hline $\begin{array}{l}\text { 5. Judgment } \\
\text { criteria }\end{array}$ & $\begin{array}{l}\text { Judgement criteria are a } \\
\text { guide for designers and } \\
\text { design manager to } \\
\text { evaluate the quality of risk } \\
\text { information before } \\
\text { transferring to the client } \\
\text { and contractor. }\end{array}$ & & $\begin{array}{l}\text { There is a lack of a set of } \\
\text { judgment criteria for the } \\
\text { employees to carry out a self- } \\
\text { assessment of their work quality } \\
\text { before transferring the output to } \\
\text { other stakeholders. }\end{array}$ \\
\hline $\begin{array}{l}\text { 6. PDCA } \\
\text { cycle }\end{array}$ & $\begin{array}{l}\text { Regular reviewing of } \\
\text { DRMP and risk } \\
\text { management during the } \\
\text { whole process. }\end{array}$ & $\begin{array}{l}\text { Few risk management } \\
\text { reviews are planned } \\
\text { during the process } \\
\text { progress. }\end{array}$ & $\begin{array}{c}\text { There is a lack of regular reviews } \\
\text { of risk management and the whole } \\
\text { DRMP before each stage } \\
\text { gateway, which causes a heavy } \\
\text { workload for both the PD and the } \\
\text { designers when the stage gateway } \\
\text { review is near. }\end{array}$ \\
\hline
\end{tabular}




\section{DISCUSSION}

The comparison between JKK and other aligned methods has brought an overview regarding the difference and novelty it offers. The analysis shows that JKK is a part of standardisation, it also covers related aspects of continuous improvement implementation. The analysis also shows that there are subtle differences between JKK and other methods.

It can possibly be used to support other methods' accomplishment. JKK and the other selected methods require the understanding of the whole process, planning the workflow, and removing constraints in process. However, JKK focuses more on the individual performance, which is normally left unmanaged. Also, in JKK, both the client's requirements and the subsequent activities' requirements are treated equally to make sure that the output is passed in perfect quality. For example, in DRMP, the designers should treat the PD, the contractor, and the project's client as customers to provide a detailed and accurate risk management schedule. Consequently, the PD's workload on approval is reduced. The contractor and the client are able to access to a proper information so that they can continue on progressing construction and maintenance stages.

The analysis of the current state of DRMP through JKK exposes the inadequate performance as it does not totally fulfill the JKK criteria. While some activities in DRMP in the chosen project to some extent cover the four criteria of JKK, none has been conducted in compliance with 'breaking down the individual activities into work units' and 'judgement criteria' features. Regarding the three prerequisites of JKK implementation, DRMP in the selected project is not sufficient. Both the PD and the designers lack a thorough understanding of the process. Also, the current state falls short regarding the open discussion and visualisation features of JKK.

\section{CONCLUSIONS}

JKK is a newly developed tool in Lean production. When applied in the construction industry, the concept of JKK has similarities with other aligned Lean construction methods in term of process improvement. However, JKK provides a unique contribution to process improvement by addressing individual intellectual work, which often remains poorly managed, at greater depth.

Up to now, JKK has been applied for an evaluation in DRMP, as a preparation step for the next phases of the action research - thorough implementation of JKK in DRMP in new projects. The results presented in this step can contribute to the 'past experience' feature of DRMP in new projects, as it provides a comprehensive overview of process problems and a direction for improvement.

\section{ACKNOWLEDGMENTS}

The authors would like to thank the company and all participants in this study for their time and support.

\section{REFERENCES}

Ballard, G., \& Tommelein, I. (2021). 2020 Current Process Benchmark for the Last Planner(R) System of Project Planning and Control. UC Berkeley. https://escholarship.org/uc/item/5t90q8q9.

Health and Safety (1999). "The Management of Health and Safety at Work Regulation 1999." $1999 \quad$ No. 3242. Accessed March 29, 2021. https://www.legislation.gov.uk/uksi/1999/3242. 
Health and Safety Executive (2015). "Construction Design and Maintenance Regulation". Accessed March 1, 2021. https://www.hse.gov.uk/pubns/priced/1153.pdf.

Heller, D. A., and Fujimoto, T. (2017). Monozukuri management In: T. Nakano (Ed.) (2017) Japanese Management in Evolution: New Directions, Breaks, and Emerging Practices, pp. 114-119. Routledge.

Kitazuka, R. E., \& Moretti, C. (2012). Jidoka. In S. Obara, \& D. Wilburn (Eds.) (2012). Toyota by Toyota: Reflections from the Inside Leaders on the Techniques That Revolutionized the Industry pp. 43-54.. CRC Press.

Koskela, L., Tezel, A., and Patel, V. (2019). "Theory of Quality Management: its Origins and History". Proc. 27 th Annual Conference of the International. Group for Lean Construction (IGLC), Pasquire C. and Hamzeh F.R. (ed.), Dublin, Ireland, pp. 13811390.

Liker, J.K. (2004). The Toyota Way. London; McGraw-Hill.

Manabe, S. (2014). "Applying the autonomation concept to white-collar departments at Toyota Motors: The basics of JKK (Ji Koutei Kanketsu)". In 22nd International Colloquium of GERPISA. Kyoto, Japan, June 2014.

Masai, P. (2017). Modeling the lean organization as a complex system (Doctoral dissertation, Université de Strasbourg).

Miron, L.I.G., Kaushik, A. and Koskela, L., (2015). "Target Value Design: The Challenge of Value Generation". In: Proc. 23rd Ann. Conf. of the Int'l. Group for Lean Construction pp. 815-825. Perth, Australia, July 29-31.

Tsao, C. C., Tommelein, I. D., Swanlund, E. S., and Howell, G. A. (2004). "Work structuring to achieve integrated product-process design". Journal of Construction Engineering and Management, 130(6), 780-789.

Perez, A. M., and Ghosh, S. (2018). "Barriers faced by new-adopter of Last Planner System ${ }^{\circledR}:$ A case study". Engineering, Construction, and Architectural Management, 25(9), 1110-1126.

Sörkvist L. (2016). "Ji koutei kanketsu (JKK) är Toyotas sätt att bygga in kvalitet genom ägarskap och ansvar" [Ji koutei kanketsu (JKK) is Toyota's way of building quality through ownership and responsibility]”. (In Swedish) https://www.larssorqvist.com/2016/05/16/ji-koutei-kanketsu-(jkk)-är-toyotas-sättatt-bygga-in-kvalitet-genom-ägarskap-och-ansvar\%C2\%A0-32061367.

Tzortzopoulos, P., Sexton, M., and Cooper, R. (2005). "Process models implementation in the construction industry: A literature synthesis". Eng. Constr. Archit. Manag., 12(5), 470-486.

Zimina, D., Ballard, G., \& Pasquire, C. (2012). "Target value design: Using collaboration and a lean approach to reduce construction cost". Construction Management and Economics, 30(5), 383-398.

Zhou, W., Whyte, J., and Sacks, R. (2012). "Construction safety and digital design: A review". Automation in Construction, 22, 102-111. 